\title{
DIAGRAMMATIC REASONING AS THE BASIS FOR DEVELOPING CONCEPTS: A SEMIOTIC ANALYSIS OF STUDENTS' LEARNING ABOUT STATISTICAL DISTRIBUTION
}

\begin{abstract}
In recent years, semiotics has become an innovative theoretical framework in mathematics education. The purpose of this article is to show that semiotics can be used to explain learning as a process of experimenting with and communicating about one's own representations (in particular 'diagrams') of mathematical problems. As a paradigmatic example, we apply a Peircean semiotic framework to answer the question of how students develop a notion of 'distribution' in a statistics course by 'diagrammatic reasoning' and by forming 'hypostatic abstractions', that is by forming new mathematical objects which can be used as means for communication and further reasoning. Peirce's semiotic terminology is used as an alternative to concepts such as modeling, symbolizing, and reification. We will show that it is a precise instrument of analysis with regard to the complexity of learning and communicating in mathematics classrooms.
\end{abstract}

KEY WORDS: concept development, diagrammatic reasoning, distribution, hypostatic abstraction, semiotics, statistics education

\section{INTRODUCTION}

It is a most fascinating moment when we can observe students learning from representations they have constructed for themselves, and experimenting with and communicating about those representations. Thus, it is no surprise that discussing the role of signs and the activities of symbolizing and modeling have become major topics in mathematics education research during the recent years. ${ }^{1}$ In a more theoretical manner, this topic has been tackled under the heading of semiotics in mathematics education. ${ }^{2}$ By reflecting on the role of signs from a semiotic point of view, the following issues have become clear. First, the possibility of mathematical knowledge depends on the possibility of representing it (Ernest, in press). Second, whatever the objects of mathematical knowledge may be, our access to those objects can be described, from an epistemological perspective, as mediated by signs. ${ }^{3}$ Third, understanding mathematics presupposes the ability both to transform representations within given 'representational systems' and to change between different systems (Duval, in press). Fourth, representations are necessary to link different areas of knowledge (Presmeg, in press). Fifth, an essential point for learning mathematics concerns the problem of 
the meaning of signs used in mathematics (Dörfler, 2000; Radford, in press; Sáenz-Ludlow, in press).

The term 'semiotics' simply means 'theory of signs' (Posner et al., 1997 ff.; Nöth, 2000), but the problem is that there are very different traditions in semiotics stemming from a variety of disciplines which have very specific interests (linguistics, philosophy, psychology, etc.). Hoffmann (in pressa) has argued that for educational purposes a most promising semiotic tradition is the one whose founding father was the American philosopher Charles S. Peirce (1839-1914): his semiotics is the only one grounded on a strong epistemological basis which is, in particular, adequate for discussing the question of how the abstract objects of mathematics are accessible for human beings. Although it has become evident that the problem fields listed above can be treated in an interesting manner by Peirce's semiotics, this semiotic theory has hardly been used to answer the question of how learning from signs is possible. ${ }^{4}$

Just this is the central question of our article. We show how Peirce's concepts of 'diagrammatic reasoning' and 'hypostatic abstractions' can be taken as a basis for a semiotic theory of learning mathematics. We elaborate on an example from a study on learning statistics, which used a Peircean semiotic framework to answer the question of how students learn statistical key concepts such as distribution by using their own representations of mathematical problems, by talking about them, and by inventing a specific language for their communication (Bakker, 2004).

From research in statistics education, we know that students have problems in reasoning about a data set as a whole without being preoccupied by the individual data points (Hancock et al., 1992; Konold and Higgins, 2003; Bakker and Gravemeijer, 2004; Ben-Zvi and Arcavi, 2001). An essential characteristic of statistics is that it can predict properties of aggregates, but not of individual values. Therefore, if students cannot see a data set as a whole, they miss the essential point of doing statistics.

The problem here is that younger students generally do not see 'five feet' as a value of the variable 'height', but as a personal characteristic of, say, Jenny. In other words, they easily say "Jenny is five feet tall," but are not inclined to think of it as "Jenny's height is five feet." Only in the latter formulation, 'height' is abstracted from a set of tall persons and hypostatized as an (abstract) entity or object of its own. Hence, students should learn to disconnect the measurement value from the object or person measured, consider data against a background of possible measurement values, and see the measured variable as an object-like entity. Doing this, they would perform a 'hypostatic abstraction' in the terms of Peirce's semiotics. This can be accomplished if students develop a notion ${ }^{5}$ of distribution. This concept is namely an organizing structure with which they can see the whole 
instead of just the elements (Cobb, 1999; Petrosino et al., 2003; Bakker and Gravemeijer, 2004).

The central problem with general or abstract concepts such as 'distribution' is that we can refer to them only by signs. We even need signs to think about them. Almost everybody who reflects on the normal distribution, for instance, will think of the famous bell shape. In other words, abstract concepts and general forms such as distribution are no Platonic 'forms' that 'exist' independently of the visible world in a 'heaven of forms'. Our thesis is, by contrast, that abstract concepts become visible in signs and in their use in mathematical activity. From this point of view, the problem of learning mathematics shifts on to the problem of how students can learn culturally accepted meanings of mathematical signs, and how they can use the signs' meanings for their own mathematical activity and communication.

In this article, we take the question of how students learned the meaning of an abstract concept of distribution as a paradigmatic example for a semiotic theory of learning. First, we explain the semiotic terminology we use. Second, we offer an analysis of students' reasoning about distribution, which is based on this semiotic approach.

\section{PeirCe's SEMiotic Terminology}

In this section, we elaborate on Peirce's semiotic theory insofar as we need it to analyze the classroom episodes. The key concepts for analyzing the role signs play in learning and communicating about mathematical problems are 'diagrammatic reasoning' and 'hypostatic abstraction'. Understanding these concepts, however, demands some reflections on Peirce's concept of sign in general, and on his famous classification of iconic, indexical, and symbolic signs in particular.

\subsection{Sign}

Signs play an important role in learning processes. According to Peirce:

All our thinking is performed upon signs of some kind or other, either imagined or actually perceived. The best thinking, especially on mathematical subjects, is done by experimenting in the imagination upon a diagram or other scheme, and it facilitates the thought to have it before one's eyes. (Peirce, NEM I, p. 122) ${ }^{6}$

The central advantage of Peirce's semiotics - in contrast to Saussure's (1916/1966) for example - is that it is based on an epistemological reflection on the role of signs as 'mediators' between objects of knowledge on the one hand, and the meaning of these objects on the other. In Peirce's semiotics, 


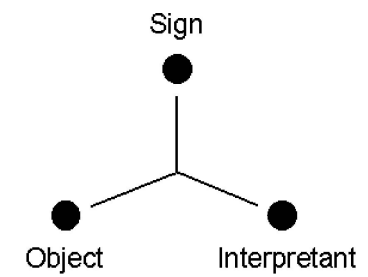

Figure 1. The sign in its triadic relation to object and interpretant.

a sign stands in a triadic relation to an object and what he called an 'interpretant' as represented in Figure $1 .^{7}$ In contrast to Saussure's dyadic relation between 'signifier' and 'signified', which he defined as "the two sides" within what he called a 'sign', for Peirce a 'sign' is integrated in a triadic relation whose most important feature is what he called the sign's 'interpretant'.

In later writings, he defined this 'interpretant' generally as "the proper significant outcome of a sign," or as its 'effect' (CP 5.473, 5.475; 1907). Thus, the interpretant can be a reaction to a sign or the effect in acting, feeling, and thinking or, in other words, the sign's 'meaning'. According to Peirce's later differentation of possible interpretants, this meaning again can either be located within an individual person or within a community. What might be called the 'objective' meaning of a sign is, for Peirce, the 'final logical interpretant' as it comes out ideally 'in the long run' of scientific communication. ${ }^{8}$ Therefore, it is important not to confuse the Peircean 'interpretant' with the 'interpreter'.

As Whitson (2003) observes, the interpretant as a reaction or effect need not be the necessary effect of a cause, but is a sign-mediated response. This effect can lead to the production of a new sign. The involvement of an interpretant implies, first of all, that the meaning of a Peircean sign is not fixed forever, but open for interpretation. Also, an object can be represented by different signs, and any sign can be interpreted in quite different ways. An action or sign-mediated effect need not be a response to one single sign, but could be the response to several signs. Conversely, the effect of interpreting a sign can also be multiple actions or the production of multiple signs. Sign-activity therefore occurs within series, webs, ${ }^{9}$ and networks of signs in which interpretants are responses to objects through the mediation of signs (Whitson, 2003). Peirce's conception of a triadic sign relation permits thus a representation also of 'non-linear' processes of interpretation which are characteristic of the complexity of classroom communication. We will present the idea of a 'semiotic space' to represent networks of representation and interpretation (see Figure 2 below). This seems to be 


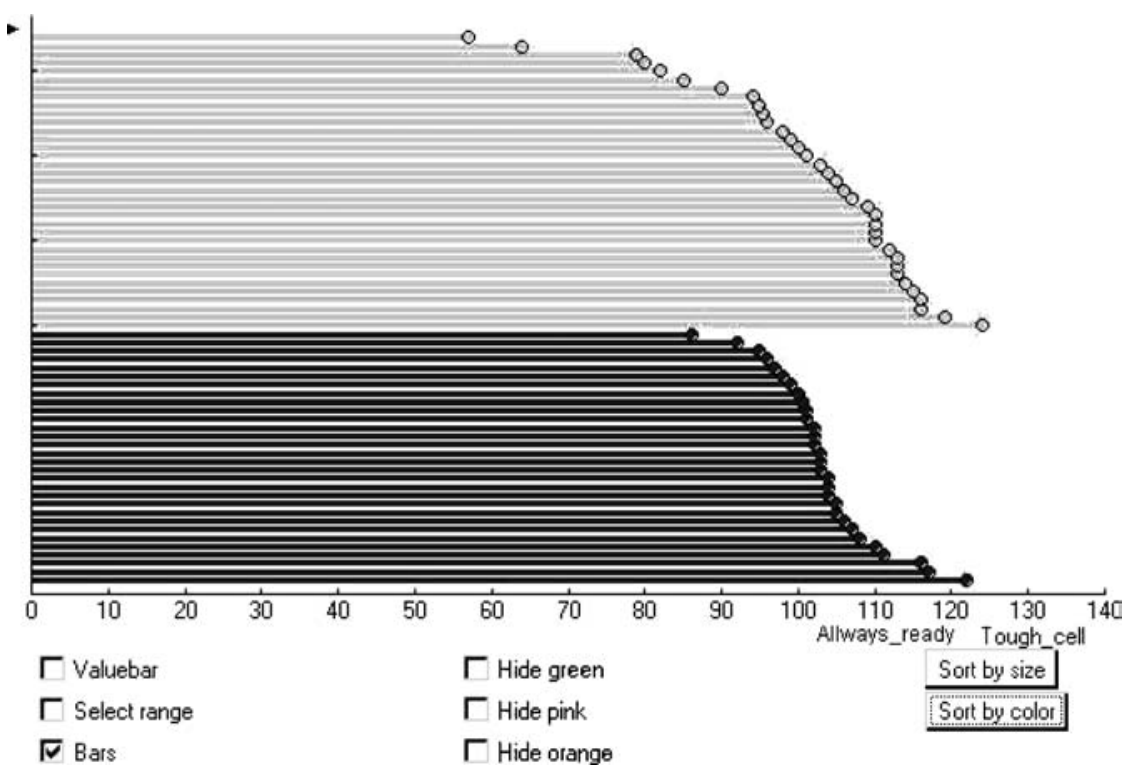

(a)

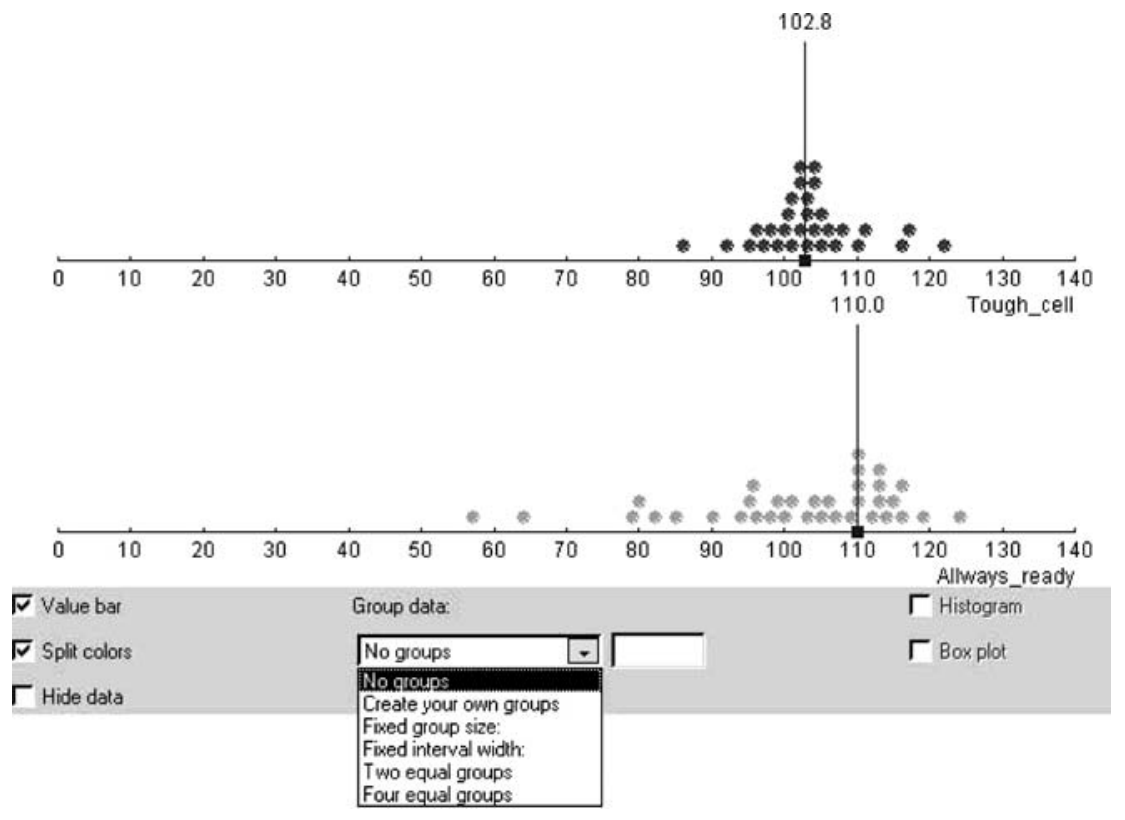

(b)

Figure 2. (a) A value-bar graph of Minitool 1, with options to sort value bars by size, by color, to hide subsets, hide bars, and select a range. The data are life spans of two battery brands in hours (see Bakker and Gravemeijer, in press). (b) A dot plot in Minitool 2, with options to organize data, for instance, into fixed interval width (histogram), into two equal groups (median), and four equal groups (box plot). This is the same data set as in Figure 2a. 
an important advantage in comparison with the linear "chains of signification' which are sometimes used for classroom analysis (Walkerdine, 1988; Whitson, 1997; Gravemeijer et al., 2000; cf. Cobb, 2002).

We give two examples to clarify how signs stand in a triadic relation to an object and an interpretant. If a student reads the sign " $2 * 5=$ " in an elementary school textbook, the interpretant can be the number 10, which might then be articulated as a new sign. In that case, the interpretant is the result of calculating the product. The interpretant is not a necessary effect as the student could make a mistake.

A more complex example is Whitson's (1997) umbrella example. Assume someone looks at a falling barometer (sign) and picks up his umbrella (interpretant). Presumably, the barometer reading is being interpreted as a sign of rain (object). Assume someone else sees him pick up his umbrella (sign) and also picks up her umbrella (interpretant). Others might decide, seeing the two leaving with umbrellas (sign), not to go out for lunch (interpretant). At a more detailed level, the barometer reading is already an interpretant which takes the needle position as a sign of atmospheric pressure. And it is easy to extend this example in many directions. For instance, the decision not to go out for lunch might be a response to the combination of seeing colleagues with umbrellas and listening to a weather report.

This umbrella example stresses that action is involved in Peirce's sign theory due to the interpretant (such as picking up an umbrella). This is why Peirce's concept of sign is often characterized as more dynamic than Saussure's (Whitson, 1997). The example also illustrates the non-linear character of sign activity, because an interpretant can well be the response to different signs, and interpreting a sign can lead to different interpretants.

A further important aspect of Peirce's signs that we need to address concerns both the possibilities that signs can be composed of other signs and that they can be components of more complex signs. That is important for an adequate understanding of his concept of a 'diagram', which we need for the central concept of 'diagrammatic reasoning'. Peirce distinguished three kinds of signs - icon, index, and symbol - which are the most famous inventions of Peirce's semiotics today. They are elementary signs, so they are not further reducible. Due to their importance, we define them in a few words.

\subsection{Icon}

The key characteristic of an icon is similarity to its object. Its main function is to represent relations. Icons represent things by imitation, for example photographs, but the resemblance may also be intellectual as by representing grammatical relations in a sentence, or by representing algebraic 
relations in an equation (Peirce, EP II, 17; NEM III, 887). Icons do not claim the existence of what they represent, but "the Form of the Icon ... must be logically possible" (CP 4.531). In CP 2.277, Peirce introduces three subcategories of icons: 'image', 'diagram', and 'metaphor' (see also Stjernfelt, 2000).

\subsection{Index}

The main function of indices is to direct someone's attention to something, exactly as in everyday language when we use the indices 'here', 'there', 'now', 'tomorrow', 'next', or the letters we use in geometry or the variables in algebra (cf. CP 1.369; NEM III, p. 887).

\subsection{Symbol}

Symbols have become associated with their objects or meanings by usage, habit, or rule. Thus, if we interpret ' 5 ' as a sign for the mathematical object 5 , it is a symbol.

A Symbol is a sign which refers to the Object that it denotes by virtue of a law, usually an association of general ideas, which operates to cause the symbol to be interpreted as referring to that Object. (Peirce, EP II, 292)

Hence, words and phrases are symbols as well as what is traditionally called a symbol in mathematics. The letter $\pi$ standing for the ratio of circumference to diameter of a circle is a symbol, but note that the letter $\pi$ printed on this page is not a symbol but only a 'replica' of the symbol. Peirce used the terms 'token' and 'type' to make this distinction. An example he often used was the word 'the'. As a word, 'the' is a type (a symbol), but the instances on this page are only tokens or replicas of it. ${ }^{10}$

\subsection{Diagram}

Peirce defines a 'diagram' as a sign "which is predominantly an icon of relations and is aided to be so by conventions. Indices are also more or less used." (Peirce, CP 4.418, 1903). Thus, a diagram is a complex sign which includes icons, indices, and symbols (as indicated by the hint at conventions). Most important, however, is its iconic character, which results from the fact that a diagram, first of all, is supposed to represent relations. Thus, geometrical figures such as triangles are diagrams because they represent particular relations of lines and vertices that are indicated by letters. Logical propositions are diagrams, because they represent certain relations of other propositions, symbols and indices (e.g. the modus ponens). 
One reason why diagrams were so important for Peirce is that one can experiment with them according to a certain syntax, since in contrast to simple icons, diagrams "should be carried out upon a ... system of representation" (Peirce, CP 4.418, 1903). Logic, algebra, axiom systems, and natural language are thus examples of representational systems. According to this syntax, any experiment performed on diagrams will necessarily lead to certain experiences (CP 5.9; cf. Hoffmann, in press-b). This does not mean that all of the students have the same experiences, nor that they need to know all conventions and hidden rules of the diagrams they make.

Is a diagram a thing on paper or a computer screen, or is it a general type? A diagram on paper is a token, a visible particular. However, if the relations of a diagram are interpreted as ideal, the diagram is a type. For example, if we prove that the angles of a triangle in Euclidean geometry sum up to $180^{\circ}$ we use a geometrical diagram as a type, because we cannot prove any general or ideal relations from just the token of one particular drawing if it is not interpreted as standing for a triangle as a general mathematical concept.

With this distinction, we can clarify the close link between statistical diagrams and concepts. If diagrams are just taught as tokens (how do you draw a box plot?), students are unlikely to conclude any general or aggregate information from them. To develop concepts, students need to learn to reason with diagrams as types. This issue leads us to Peirce's concepts of diagrammatic reasoning and hypostatic abstraction.

\subsection{Diagrammatic reasoning}

For Peirce, diagrammatic reasoning involves three steps.

1. The first step is to construct a diagram (or diagrams) by means of a representational system such as Euclidean geometry, but we can also think of diagrams in computer software or of an informal student sketch of a statistical distribution. Such a construction of diagrams is motivated by the need to represent the relations that students consider significant in a problem. This first step may be called 'diagrammatization'.

2. The second step of diagrammatic reasoning is to experiment with the diagram (or diagrams). Any experimenting with a diagram is being executed within a representational system and is a rule or habit-driven activity (today we would stress that this activity is situated within a practice). What makes experimenting with diagrams important is the rationality that is immanent in them (Hoffmann, in press-b). The rules define the possible transformations and actions, but also the constraints of operations on diagrams. Statistical diagrams such as dot plots are also 
bound to certain rules: a dot has to be put above its value on the $x$-axis and this remains true if the scale is being changed. Peirce stresses the importance of doing something when thinking or reasoning with diagrams:

Thinking in general terms is not enough. It is necessary that something should be DONE. In geometry, subsidiary lines are drawn. In algebra, permissible transformations are made. Thereupon the faculty of observation is called into play. (CP 4.233)

3. The third step is to observe the results of experimenting and reflect on them. As Peirce wrote, the diagram constructed by a mathematician "puts before him an icon by the observation of which he detects relations between the parts of the diagram other than those which were used in its construction" (NEM III, 749). In this way, he can "discover unnoticed and hidden relations among the parts" (CP 3.363; see also CP 1.383). The power of diagrammatic reasoning is that "we are continually bumping up against hard fact. We expected one thing, or passively took it for granted, and had the image of it in our minds, but experience forces that idea into the background, and compels us to think quite differently" (CP 1.324; cf. Hull, 1994).

Diagrammatic reasoning, in particular the reflection step, is what can bring in the 'new' thing. New implications within a given representational system can be found, but possibly the need is felt to construct a new diagram that better serves its purpose, or even to develop the used representational system itself. If new concepts are created in this innovative step, we are confronted with what Peirce discussed under the heading of 'hypostatic abstraction'.

\subsection{Hypostatic abstraction}

Peirce distinguished two types of abstraction, 'prescissive' and 'hypostatic' abstraction. Prescissive abstraction is dispensing with certain features; for example, if we use a geometrical line we dispense with the width of the line (CP 4.235). Hypostatic abstraction, by contrast, is regarding a certain characteristic of a set of objects as a new object. ${ }^{11}$ For Peirce, "an 'object' means that which one speaks or thinks of" (NEM I, 124). Hypostatic abstraction puts "an abstract noun in place of a concrete predicate" (NEM IV, 160). This is not just a linguistic trick, but a genuinely creative act that allows the making of discoveries with new eyes. For Peirce, "[Hypostatic] abstraction is an essential part of almost every really helpful step in mathematics" (NEM IV, p. 160).

Note that the term 'abstraction' can both mean the process and the product (cf. Noss and Hoyles, 1996, 123). In this paper we use the term 
'hypostatic abstraction' for a product (as the result of a process). Let us consider examples to provide a clearer image of what this concept of hypostatic abstraction entails.

If we change "honey is sweet" into "honey possesses sweetness" (CP 4.235) and consider 'sweetness' as an object that we can talk about, we have a simple example of hypostatic abstraction. In the first sentence, 'sweet' is a predicate of something, but in the second sentence, 'sweetness' is considered as an object in itself. In mathematics, a collection is a hypostatic abstraction. And cardinal numbers are hypostatic abstractions derived from a predicate of a collection (Peirce, CP 5.534).

Another example of hypostatic abstraction is that of forming a notion of 'spread' as described by Bakker (2004). Students first used predicates to characterize the relative position of the dots in a dot plot as "the dots are spread out" (this can be called 'predication'). The dots are objects that refer to data values and 'spread out' is a predicate of the dots. Later students write that "the spread is large." In that case, spread signifies a new object that is characterized with the predicate "large'.

The central point of diagrammatic reasoning is that it creates the basis for forming hypostatic abstractions, that is new objects such as those signified by the terms dots, shape, or spread. Hypostatic abstraction takes place when part of a diagram becomes perceived as an entity on its own, a new object. The central point of hypostatic abstraction, in turn, is that the new objects formed by this process can be used as means for further diagrammatization, and for further steps of learning. For instance, once the shape of a distribution is hypostatized as a 'bump', it can next be used for shifting bumps when comparing distributions. With regard to this point, Otte (1997, p. 360) coined the term 'complementarity' or 'dialectic of means and objects' as the essence of mathematical activity. Learning abstract concepts, from this point of view, means creating new objects by hypostatic abstraction and using them as new means of mediation between the subject and the object of cognition. These new objects - as 'independent' from the subject's activity - are the starting point for further hypostatic abstractions, forming thus an ongoing process of generalizing mathematical concepts and structures that 'echoes' the history of mathematics.

\section{BACKGROUND INFORMATION ON THE TEACHING EXPERIMENT}

The seventh-grade class we report on in this article consisted of 28 students (age 12-13) in the pre-university stream of a Dutch public school of about 800 students. The classroom-based teaching experiment lasted 15 lessons of 50 min each. The data corpus consisted of audiorecordings of the lessons, 
student work, field notes, a final test, and mini-interviews with all students. These mini-interviews lasted from about $20 \mathrm{~s}$ to $4 \mathrm{~min}$, and were meant to find out how students thought using statistical concepts and diagrams. The teaching experiment was part of a larger design research study (Bakker, 2004) in which a 'hypothetical learning trajectory' (Simon, 1995) was developed with the end goal that students would learn to reason about the shape of a distribution. In the 10 lessons prior to the episodes we describe here, students had learned to compare distributions using their notions of mean, median, majority, outliers, range, and had developed a language in which they could express spread and density issues using such terms as "here the dots are spread out" and "there they are close together." In 5 of the 10 lessons, students had used simple computer tools that were called Minitools (see e.g. Cobb, 1999; Bakker and Gravemeijer, 2004). The first Minitool supplies a bar graph in which each bar has a length corresponding to the data value it represents (Figure 2a); the second Minitool provides a dot plot (Figure 2b). In the first Minitool, students can organize data, for instance by sorting or hiding subsets of data, and by sorting the data by size. In the second Minitool, students can organize data with different options, for instance making their own groups, two equal groups (precursor to the median), four equal groups (precursor to box plot), and fixed interval width (precursor to histogram).

\section{ANALYSIS OF STUDENTS' REASONING WITH THE BUMP}

Because reasoning about distribution as a whole and an object-like entity was the end goal of the hypothetical learning trajectory, we focus the analysis on students' reasoning that came closest to this end goal: their reasoning with the 'bump'. In this section, we first analyze how the bump became a topic of discussion in the 11th lesson. Then we look back at students' relevant prior experiences and look forward to how students reasoned with bumps in later lessons.

\subsection{The bump became a topic of discussion}

Because it was Mike's diagram in Figure 3 that gave rise to the discussion about the bump, we first analyze his diagrammatization, the first step of diagrammatic reasoning. He explained how he made his diagram $\left(S_{2}\right.$ in Figure 4$)$ from the available data values $\left(S_{1}\right.$ in Figure 4$)$ as represented in a table, which was filled in by the students. Referring to his diagram, he said during the class discussion:

Look, you have roughly, averagely speaking, how many students had that weight and there I have put a dot. And then I have left [ $y$-axis] the number of students. 


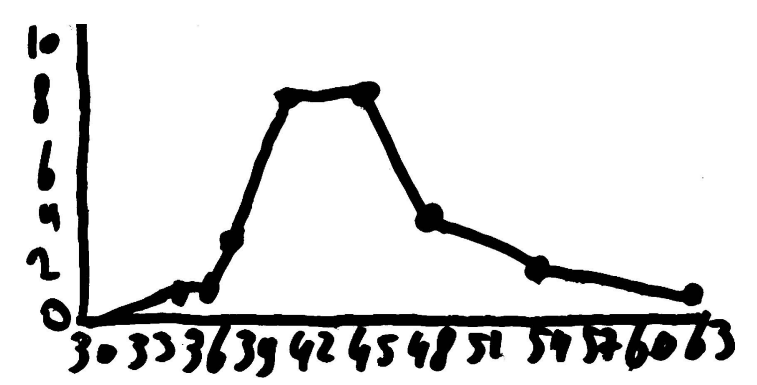

Figure 3. Mike's idiosyncratic line graph of the class's weights.

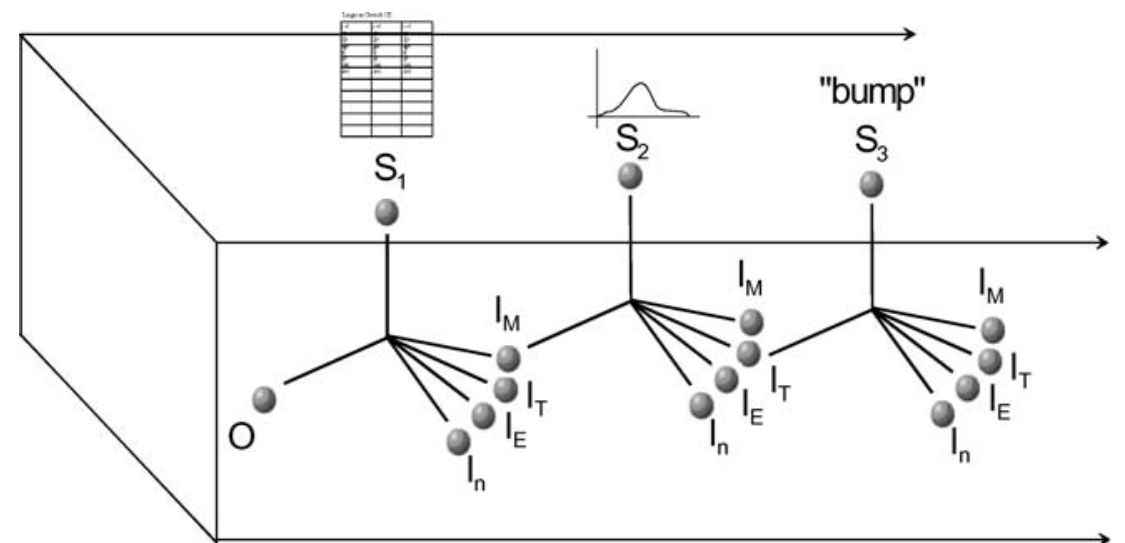

Key: "S" represents signs. "O" stands for the "object" (the students' weights) which is represented in a certain respect by the different signs (a table, a graph, and a new term) which are for themselves "interpreted" in various ways. The "I's" signify various "interpretants" in class (of Mike, teacher, etc.).

Figure 4. Semiosis over three signs (produced by the students, by Mike, and by the teacher) within a semiotic space.

There is one student who weighs about $35[\mathrm{~kg}]$, and there is one who weighs 36 , and two who weigh 38 roughly.

We first analyze his diagrammatization on an individual level and then analyze how this sign functioned collectively in the class discussion (as Whitson's umbrella example shows, the episode can be analyzed on different levels of detail). Judging from his explanation, Mike interpreted data values in the table as standing for students' weights (O: objects). This interpretation, which is not visible for us, as it is something that happens at first only in his mind, is called his 'interpretant' $\left(\mathrm{I}_{M}\right)$ in Peircean terms. What is observable, however, is the explanation of his action of constructing his diagram and the result of it, the diagram itself. It is this explanation which permits formulating a hypothesis about what the interpretant he had formed might have been. From a semiotic point of view, we could say Mike 'transformed' his interpretant into a new sign, his diagram. After 
grouping the data values and counting the frequency of each group, Mike represented those groups of weight data values (objects) with dots (signs), and this led him to the next action of connecting the dots to what looks like a frequency polygon (see Figure 3). Because of the irregular step size it is not a conventional way of representing a frequency distribution.

We now turn to the analysis on the class level by considering what we have called the 'semiotic space' of classroom communication (Figure 4). In the hypothetical learning trajectory, we had aimed for reasoning about shape assuming that it would support reasoning about the whole data set (an aggregate view) instead of just individual data values (a case-oriented view). When the teacher saw Mike's graph, she realized that this was an opportunity to initiate a discussion on shape as intended in the hypothetical learning trajectory. When collectively comparing Mike's and Emily's graph (Figure 5), she asked:

Teacher: What can you easily see in this graph [Mike made]?

Laura: Well, that the average, that most students in the class, uhm, well, are between 39 and, well, 48 [kg].

Teacher: Yes, here you can see at once which weight most students in this class roughly have, what is about the biggest group. Just because you see this bump here. We lost the bump in Emily's graph.

This is how the teacher introduced the term 'bump' $\left(S_{3}\right)$ to refer to the specific shape in Mike's diagram $\left(\mathrm{S}_{2}\right)$. But what exactly is this shape? Depending on how it was interpreted, it could be anything ranging from a visual image of a bump to a symbol of a slightly skewed unimodal distribution. In other words, the shape can have different functions, as we clarify in the following.

The teacher herself probably interpreted the shape as standing for a unimodal distribution. The students probably first interpreted the sign 'bump' as a metaphor because of the resemblance of the shape to a bump. The teacher then turned to Emily's graph. This is a value-bar graph, just as Minitool 1, but with the value bars turned at an angle. Each shorter and lighter bar stands for a weight data value; each longer and darker value bar for a height data value. The data values of boys and girls are represented by different colors. The horizontal lines represent means of various subgroups. By asking what happened to the bump in Emily's graph (Figure 5), the teacher stimulated students to reflect on the shape as a diagram representing relations between data values. For example, when the teacher asked about the bump in Emily's graph, Nathalie explained:

Nathalie: The difference between ... they stand from small to tall, so the bump, that is where the things, where the bars [from Emily's graph] are closest to one another. 


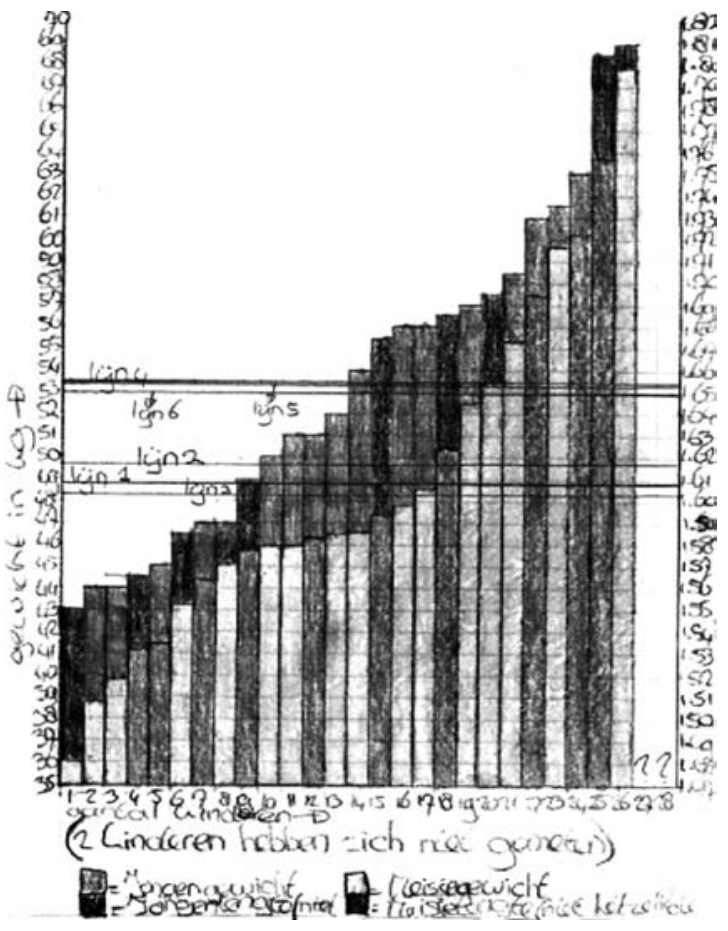

Figure 5. Emily's graph.

Teacher: What do you mean, where the bars are closest?

Nathalie: The difference, the endpoints [of the bars], do not differ so much with the next one.

And Evelien added:

Evelien: If you look well, then you see that almost in the middle, there it is straight almost and uh, [teacher points at the horizontal part in Emily's graph] yeah that.

Teacher: And that is what you [Nathalie] also said, uh, they are close together and here they are bunched up, as far as (...) weight is concerned.

Evelien: And that is also that bump.

In our interpretation, the object that these students referred to was a group of values that were close together and that they had previously also called the 'majority'. The mental transformation of part of Emily's diagram into the bump of Mike's diagram or vice versa can be interpreted as a form of mental experimentation with diagrams. The episode therefore includes the three steps of diagrammatic reasoning: diagrammatization, experimentation, and reflection. This kind of diagrammatic reasoning 
has been a basis for the students to think about some essential aspects of statistical representations. By interpreting signs in a kind of 'interpreting game' (Sáenz-Ludlow, 2003), by communicating about these signs, and by producing new signs, the students had an opportunity to learn statistical concepts.

Most interesting, perhaps, is the significance the term 'bump' has received in this situation. The term is a hypostatic abstraction as defined above according to Peirce. Within the classroom discourse, the term 'bump' does, of course, not yet refer to a very definite object and it is very unlikely that students' interpretations of the bump were all the same. Yet the step of reasoning about shapes using the term 'bump' was an important step on the way to reasoning about distributions.

\subsection{Where it came from}

Mike's actions of grouping data values and drawing a line through dots have a history. In his explanation he talks about average, which might imply that his grouping action is inspired by averaging numbers in the first lessons of the teaching experiment. They had learned to estimate the mean of a data set visually with a vertical reference line in plots such as Figure 6. During an activity on battery life spans, students had learned to talk about groups of data (e.g. "the high values of brand $K$ "). It is also possible that Mike's experience with the Minitool 2 option of grouping data (e.g. making your own groups; cf. Figure 2b) inspired him to group the data. His next action was making a $y$-axis with frequencies and connecting the dots as in a line graph (which, as we mentioned, is not a conventional way of representing data). As Walkerdine (1988) and Cobb (2002) note, signs such as the bump should be viewed within a particular practice, that is for a particular purpose

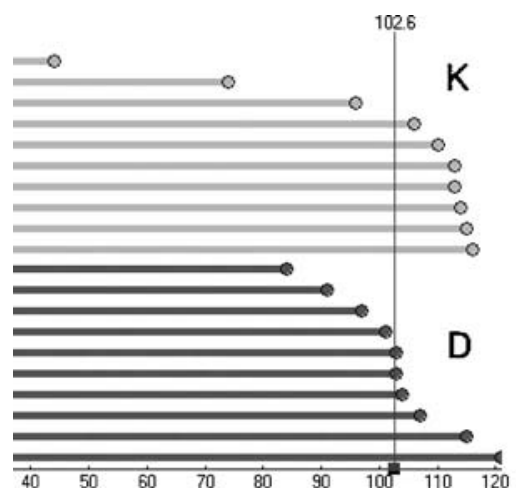

Figure 6. The 'bump' as a means of reasoning in the battery context. 
with other mathematical practices in the background. We therefore note that Mike had learned to make line graphs in mathematics lessons where such graph practices had been established. In the statistics lessons the students had never used frequency polygons or line graphs before.

The background of Emily's diagram (Figure 5) must be her experience with Minitool 1; she only turned the bars to a vertical position. The horizontal lines she drew represent the weight and height means of boys, girls, and the whole class. This action most likely stems from estimating averages with a reference line in Minitool 1 in earlier lessons. In other words, due to their experimenting with the Minitools students were probably able to construct these diagrams and reason sensibly about them.

When observing in the classroom, we thought that the 'bump' referred to the distribution as a whole, as we intended in the hypothetical learning trajectory. It was by going back to the history of students' actions and their exact formulations that we realized that students were just referring to the values that were close to one another and not to the whole distribution when using the term 'bump' (students also referred to this group as the 'majority' or the 'average'). The transcript lines above of Nathalie and Evelien as well as transcripts of later lessons support this claim.

The fact that several students were able to understand the link between Emily's and Mike's diagrams is probably due to their experimentation experience with the Minitools and their reasoning with the hypostatic abstractions they had formed before. By solving statistical problems with diagrams they had developed a language with which they could reason with $^{12}$ hypostatic abstractions such as majority, average, range, low and high values. It is likely that these notions formed the basis for interpreting the bump, because the bump was initially interpreted as the majority or average group of the data.

\subsection{Where it went}

In the next (12th) lesson, when students revisited the problem on battery life spans of two brands $D$ and $K$ (Figure 6), some students used the term 'bump' to indicate a specific group of the data and the straight part in Minitool 1. This indicates that they used the 'bump', a hypostatic abstraction, as a means for reasoning. For example:

Laura: But then you see the bump here, let's say [Figure 6].

Yvonne: This is the bump [pointing at the straight vertical part of the lower ten bars left of the letter $D$ )].

Researcher: Where is that bump? Is it where you put that red line [the vertical reference line]? 
Laura: Yes, we used that reference line for it (...) to indicate it, indicate the bump. If you look at green [brand $K$, the upper ten value bars], then you see that it lies further [to the right], the bump. So we think that green is better, because the bump is further up.

These examples illustrate that students did not interpret the bump just as a metaphor because there is no likeness of a bump with the straight part in the diagram. The bump had become a symbol for several students, standing for the middle group of values that were close together, and this was by convention or habit grown out of the previous lesson. Apart from the term 'bump', students also used 'majority' or 'average' to refer to such groups of values that were close together. This 'majority' is not a very well defined object, but at least students talk and think about a group of data values with fuzzy borders. Note, however, that it is possible to talk about the bump because there are also less frequent values that do not belong to the majority. The fact that Laura and Yvonne use the term 'bump' to indicate the straight part in Minitool 1 (Figure 6) shows that they have mentally constructed an object that is roughly the majority. In other words, they use the bump as a means in comparing distributions. ${ }^{13}$

We now give more examples of students' experimenting with and reflecting on diagrams in the 13th lesson. In that lesson, the hypothetical learning trajectory aimed at letting students use the term 'bump' for the whole distribution and stimulating them to use shapes as means in their reasoning. This aim was inspired by a remark of Sfard (1991) that to stimulate the formation of a concept as an object, we have to create a situation in which students need such a concept as an object and not merely as a procedure or a batch of individual objects. We asked students about a larger sample to make the stability of the shape of a distribution a topic of discussion and we asked about the weight graph of older students to stimulate that students would shift the bump as an object.

In the 13th lesson, there were indeed indications that several students came to relate the 'bump' to the whole distribution instead of just the 'majority' or 'average' group. Emily, for example, incorporated the 'outliers' in her reasoning about the shape of the bump, with which she meant very low or high values (statisticians reserve the term 'outliers' for exceptional or suspect values outside the distribution).

Researcher: If you would measure all seventh graders in the city instead of just your class, how would the graph change, or wouldn't it change?

Emily: Then there would come a little more to the left and a little more to the right. Then the bump would become a little wider, I think. [She explained this using the term 'outliers'.] 
Researcher: Is there anybody who does not agree?

Mike: Yes, if there are more children, then the average, so the most, that also becomes more. So the bump stays just the same.

Anissa: I think that the number of children becomes more and that the bump stays the same.

Emily explained that the bump would become wider because of new 'outliers' (extreme values). This implies that she used the term 'bump' for the whole shape instead of just the majority or average group. What is interesting about Mike and Anissa's remarks is that they seemed to have a sense of the shape's stability even if the sample grows. If they had interpreted the bump as just the middle group, they would probably have thought that the bump would grow higher because of there being more dots.

It could well be that students started to use the term 'bump' for the whole distribution because of the discourse on what students called 'outliers' (low and high values that are less frequent than average values). The students could only see a 'majority' because there were values that occurred less often, which they called 'outliers'. These high or low values are high or low because they differ considerably from the majority (the bump) and the bump is a bump because there are also values that do not occur so often. This mentally dividing data sets into three groups seems to be a natural way for students to think of data sets, as we inferred from the analyses of other lessons.

The reasoning with bumps in larger samples could be seen as experimenting with a diagram in the mind. This also holds for students' reasoning in reaction to the following question that was meant to stimulate a shift of the bump as a whole and as an object-like entity.

Teacher: What would a graph of the weights of eighth graders [instead of seventh graders] look like?

Gerdien: The bump would be more to the right.

If Gerdien mentally shifted the whole bump to the right, the object she referred to was probably the whole distribution and not just the 'majority' of the data values. As intended in the hypothetical learning trajectory, the question had so to speak created a need in which students could best operate with the bump as one object, the whole distribution.

As we wrote in the previous section, diagrammatic reasoning offers the opportunity for hypostatic abstraction, the formation of objects (what can be talked about or thought of). In this section we encountered steps of hypostatic abstraction: the bump as standing for a majority and later for the whole distribution. In reasoning about the bumps students used hypostatic abstractions such as majority, outliers, and average, which they had formed in previous lessons, but still needed refinement. This means that the process 
of developing a notion of distribution involves several steps of hypostatic abstraction and a gradual refinement of what the formed objects are. The way a few students reasoned about and with the bump shows that they developed a notion that comes close to the concept of distribution: they used the bump to model hypothetical data. Some probably realized that the shape would be stable across larger sample sizes.

\section{CONCLusions}

In this article, we have applied a semiotic framework for analyzing students' learning. The episodes were framed as instances of diagrammatic reasoning, which in turn formed the basis for hypostatic abstraction. The key steps of diagrammatic reasoning are making a diagram, experimenting with it, and reflecting on the results. During this diagrammatic reasoning, hypostatic abstractions such as majority, average, and shape can be taken as objects in the discourse, and next used as means in communication and further reasoning. In our paradigmatic example, we focused on the emergence of the bump.

The analysis shows that diagrammatization depends on a variety of interpretations in the class (semiotically hypostatized as interpretants in Figure 4), and that it can involve multiple actions. Mike, for example, informally grouped the weight data values, used dots at certain positions to signify these groups and the frequencies, and connected the dots to one shape. All of these actions have a history, either in the teaching experiment (grouping data, using dots) or in prior mathematics lessons (line graph). During the reflection on the diagrams, the teacher used the term 'bump' to make this shape the topic of discussion (or in other words: an object). Students might have first interpreted the bump as an iconic sign (a visual image or a metaphor), but the analysis shows that the meaning of the bump changed from the 11th to the 13th lesson, at least for several students. In the 11th lesson, students used the bump to refer to a group of values that were close together in the middle part of the graphs. The interesting thing is that the same data set looks so different in different student graphs. By asking what had happened to the bump in Mike's graph in Emily's graph, the teacher stimulated students to formulate what exactly the object was which looked like a bump in Mike's graph and as a straight line in Emily's graph. This object, a group of values that were close together, can be seen as a hypostatic abstraction. We can also speak of it as the common conceptual structure underlying aspects of both graphs.

In the 12th lesson, several students used the term 'bump' even for a group of data if there was no visual bump, for instance when they referred 
to the vertical straight part in value-bar graphs as a bump (Figure 6). This implies that the bump was not just a visual characteristic, but had become a conceptual object and even a means in their reasoning, for instance in arguing which of the two battery brands was better.

In the 13th lesson, several students referred to 'bump' as the whole shape, whereas before they only referred to the high part of the mound shape (a group of values being close together). The development of the bump as a whole was probably stimulated by questions about hypothetical situations in which students needed the bump as an object-like entity, as anticipated in the hypothetical learning trajectory. When we asked about the shape of the graph with a much larger sample, one student argued that it would grow wider if the sample got bigger because there would be more very low and high values and other students reasoned that the bump would stay the same because there would also be more 'average' values. Students also answered the question of what would happen if students of a higher grade would be measured. One student said that the bump would be shifted to the right. In that sense, the bump had become an object encapsulating the data set as a whole, which in turn can be operated with. Several students were able to relate aspects of that shape to distribution aspects such as average, majority, groups of values, and several acknowledged the stability of the shape across sample size. They even hypothesized on the shape of a large sample, which means they modeled hypothetical situations with a notion of distribution.

The analysis presented here can be taken as a paradigmatic example of explaining learning as a process of diagrammatic reasoning in which opportunities for hypostatic abstraction occurred. Using Peirce's semiotics, we realized that the hypothetical learning trajectory could be seen as progressive diagrammatic reasoning about distribution aspects (including average, spread, and shape). This process has been described by the three core steps of diagrammatic reasoning: making a diagram, experimenting with it, and reflecting on the results. Our analyses suggest the following recommendations.

First, it is clear students need to diagrammatize - make their own diagrams that make sense to them, but also learn powerful conventional types of diagrams. To stimulate aggregate views on data, we asked students to make diagrams according to aggregate features, e.g. of an unreliable battery brand with a high life span. In another class, we also asked students to make diagrams with small or large spread, and even a diagram with a large range but small spread. This can be called diagrammatization according to aggregate features.

Second, students need to experiment with diagrams. Educational software such as the Minitools can be useful in this stage of diagrammatic 
reasoning. The software should offer diagrams that students understand, but it should also offer opportunities for learning more advanced, culturally accepted diagrams.

Third, reflection should be stimulated. Throughout the research we noticed that the best reasoning occurred during teacher-directed class discussions that were not in the computer lab. One of the core goals is that students learn to describe ('predicate') and predict aggregate features of data sets, because that is an essential characteristic of statistical data analysis. This implies that students should be stimulated to describe features of data sets and diagrams, and predict features of hypothetical situations.

Throughout this article we have argued that diagrammatic reasoning creates opportunities for developing concepts or, more generally, for forming hypostatic abstractions. This way of forming objects can be stimulated in different ways. First, predicates should become topics of discussion so that they can be taken as entities in themselves. For example, talking about 'most' data can lead to talking about the 'majority'; describing how dots are 'spread out' can lead to saying that "the spread is large." Second, students should be stimulated to be precise about what they refer to. For instance, if they use indexical words such as 'that' or 'it', it is possible that they cannot express or do not know to which object they exactly refer. In retrospect, we concluded we should have asked in which range exactly students saw the majority and where they saw the bump in order to make the 'majority' a clear topic of discussion. Precisely defining the topic of discussion is thus integral to conceptual development. Third, we should create situations in which students need conceptual objects as means of reasoning (cf. Sfard, 1991). When the teacher asked what would happen to the diagram if data of an older class were shown, students were stimulated to use the bump as an object and shift it to the right as a whole. Fourth, comparing multiple representations (cf. Van Someren et al., 1998) of one thing can support students in thinking of the common structure (a hypostatic abstraction) underlying these representations. In the 11th lesson, students compared several diagrams of one and the same data set and the teacher stimulated them to think of why the bump in one diagram looked differently in another diagram (Emily's). In explaining this, students referred to what the bump and the value bars stood for: values that were close to each other.

Diagrams are, in Peirce's epistemologically based semiotics, not only means of communication, but more fundamentally means of thought, of understanding, and of reasoning. From that epistemological point of view, the essence of diagrammatic reasoning can be seen in the fact that it offers the basis for hypostatic abstractions - cognitive means that can be used and developed in further diagrammatic reasoning. 


\section{ACKNOWLEDGMENTS}

The research was funded by the Netherlands Organization for Scientific Research under grant number 575-36-003B. The opinions expressed in this chapter do not necessarily reflect the views of the Organization. We thank Mieke Abels for teaching in this project, Koeno Gravemeijer, Gellof Kanselaar, and Jan de Lange for their advice during the research and comments on earlier versions of this manuscript, and anonymous reviewers for their helpful suggestions.

\section{NOTES}

1. Cf. for instance Janvier, 1987; Goldin and Kaput, 1996; Seeger, 1998; Cobb et al., 2000; Gravemeijer et al., 2000; Hitt, 2002, and the papers published in two Special Issues on "Representations and the Psychology of Mathematics Education," Journal of Mathematical Behavior 1999 (17), Numbers 1 and 2, edited by Gerald Goldin and Claude Janvier.

2. Whitson, 1997; Radford, 2000; Hoffmann, 2000; Anderson et al., 2003; and SáenzLudlow, 2003.

3. Otte, in press; Roth, 2003; Steinbring, in press.

4. For a more theoretical discussion of this question see Kadunz, 2003; Hoffmann, 2003, in press-b,c; Sáenz-Ludlow, in press.

5. We use the term 'notion' for students' notions of statistical concepts and the term 'concept' for concepts as they are defined or understood within the communities of statisticians, educators, or semioticians.

6. Following common practice, we refer to Peirce's Collected Papers as CP with volume number and section, to the New Elements of Mathematics as NEM with the volume number, and to the Essential Peirce edited by the Peirce Edition Project as EP.

7. The form of the triadic relation used in the diagram (like a Mercedes star) is justified by Peirce, NEM IV 307 ff. (c. 1893), and Peirce, SEM II, 137 (1903).

8. For a more detailed explication of Peirce's 'interpretant' see Hoffmann (in press-a, Section 13).

9. Cf. the notion of 'webbing' (Noss and Hoyles, 1996).

10. Token is therefore very similar to what many researchers today call an 'inscription' (e.g. Roth and McGinn, 1998).

11. For Peirce, reification and hypostastic abstraction were the same; hypostasis is just the Greek equivalent of the Latin reificatio, the making of an object. Thus, there is no problem to link this discussion with Sfard's (1991) use of the term 'reification'.

12. We use the phrase 'reason about' if students mention properties of objects and 'reason with' if they use these objects as tools in their reasoning.

13. Once students reached such understanding they might come to see that the position of the bump can be measured with a median, because the median is generally somewhere in that bump, even in skewed distributions (unlike the mean). See also Cobb et al. (2003). 


\section{REFERENCES}

Anderson, M., Sáenz-Ludlow, A., Zellweger, S. and Cifarelli, V.V. (eds.): 2003, Educational Perspectives on Mathematics as Semiosis: From Thinking to Interpreting to Knowing, Legas, Ottawa, Canada.

Bakker, A.: 2004, Design Research in Statistics Education; On Symbolizing and Computer Tools, CD Beta, Utrecht, The Netherlands.

Bakker, A. and Gravemeijer, K.P.E.: 2004, 'Learning to reason about distribution', in D. BenZvi and J. Garfield (eds.), The Challenge of Developing Statistical Literacy, Reasoning, and Thinking, Kluwer Academic, Dordrecht, The Netherlands, pp. 147-168.

Ben-Zvi, D. and Arcavi, A.: 2001, 'Junior high school students' construction of global views of data and data representations', Educational Studies in Mathematics 45, 35-65.

Cobb, P.: 1999, 'Individual and collective mathematical development: The case of statistical data analysis', Mathematical Thinking and Learning 1(1), 5-43.

Cobb, P.: 2002, 'Modeling, symbolizing, and tool use in statistical data analysis', in K.P.E. Gravemeijer, R. Lehrer, B. van Oers and L. Verschaffel (eds.), Symbolizing, Modeling and Tool Use in Mathematics Education, Kluwer Academic, Dordrecht, The Netherlands, pp. 171-196.

Cobb, P., Yackel, E. and McClain, K. (eds.): 2000, Symbolizing and Communicating in Mathematics Classrooms. Perspectives on Discourse, Tools, and Instructional Design, Erlbaum, Hillsdale, NJ.

Dörfler, W.: 2000, 'Means for meaning', in P. Cobb, E. Yackel and K. McClain (eds.), Symbolizing and Communicating in Mathematics Classrooms. Perspectives on Discourse, Tools, and Instructional Design, Erlbaum, Hillsdale, NJ, pp. 99-131.

Duval, R.: in press, 'The cognitive analysis of problems of comprehension in the learning of mathematics', in A. Sáenz-Ludlow and N. Presmeg (eds.), Special issue on Semiotic Perspectives on Epistemology and Teaching and Learning of Mathematics, Educational Studies in Mathematics 61(1-3).

Ernest, P.: in press, 'A semiotic perspective of mathematical activity: The case of number', in A. Sáenz-Ludlow and N. Presmeg (eds.), Special issue on Semiotic Perspectives on Epistemology and Teaching and Learning of Mathematics, Educational Studies in Mathematics 61(1-3).

Goldin, G.A. and Kaput, J.J.: 1996, 'A joint perspective on the idea of representation in learning and doing mathematics'. In L.P. Steffe, P. Nesher, P. Cobb, G.A. Golding and B. Greer (eds.), Theories of Mathematical Learning, Erlbaum, Mahwah, NJ, pp. 397430.

Gravemeijer, K., Cobb, P., Bowers, J. and Whitenack, J.: 2000, 'Symbolizing, modeling and instructional design', in P. Cobb, E. Yackel and K. McClain (eds.), Symbolizing and Communicating in Mathematics Classrooms, Erlbaum, Mahwah, NJ, pp. 225273.

Hancock, C., Kaput, J.J. and Goldsmith, L.T.: 1992, 'Authentic enquiry with data: Critical barriers to classroom implementation', Educational Psychologist 27(3), 337-364.

Hitt, F. (ed.): 2002, Representations and Mathematics Visualization, Departamento de Matemática Educativa, Cinvestav-IPN, Mexico City, Mexico.

Hoffmann, M.H.G. (ed.): 2000, 'Lernen als Zeichenprozess', Special Issue Zeitschrift für Semiotik 22(1).

Hoffmann, M.H.G.: 2003, Peirce's "Diagrammatic reasoning" as a solution of the learning paradox, in G. Debrock (ed.), Process Pragmatism: Essays on a Quiet Philosophical Revolution, Rodopi, Amsterdam, pp. 121-143. 
Hoffmann, M.H.G.: in press-a, 'Commentary paper: What is a "semiotic perspective"?', in A. Sáenz-Ludlow and N. Presmeg (eds.), Educational Studies in Mathematics, Special Issue on "Semiotic Perspectives on Epistemology and Teaching and Learning of Mathematics", 61(1-3).

Hoffmann, M.H.G.: 2004, 'How to get it. Diagrammatic reasoning as a tool of knowledge development and its pragmatic dimension', Foundations of Science 9(3), 285-305.

Hoffmann, M.H.G.: 2005, 'Signs as means for discoveries. Peirce and his concepts of "diagrammatic reasoning", "theorematic deduction", "hypostatic abstraction", and "theoric transformation", in M.H.G. Hoffmann, J. Lenhard and F. Seeger (eds.), Activity and Sign - Grounding Mathematics Education, Springer, New York, pp. 45-56.

Hull, K.: 1994, 'Why hanker after logic? Mathematical imagination, creativity and perception in Peirce's systematic philosophy', Transactions of the Charles S. Peirce Society 30, 271-295.

Janvier, C. (ed.): 1987, Problems of Representation in the Teaching and Learning of Mathematics, Erlbaum, Hillsdale, NJ.

Kadunz, G.: 2003, 'Geometrielernen mit computergenerierten Repräsentationen. Zur Bedeutung von Modulen', in M.H.G. Hoffmann (ed.), Mathematik Verstehen -Semiotische Perspektiven, Franzbecker, Hildesheim, Germany, pp. 95-118.

Konold, C. and Higgins, T.: 2003, 'Reasoning about data', in J. Kilpatrick, W.G. Martin and D. Schifter (eds.), A Research Companion to Principles and Standards for School Mathematics, National Council of Teachers of Mathematics, Reston, VA, pp. 193215.

Noss, R. and Hoyles, C.: 1996, Windows on Mathematical Meaning, Kluwer Academic, Dordrecht, The Netherlands.

Nöth, W.: 2000, Handbuch der Semiotik, Metzler, Stuttgart und Weimar.

Otte, M.: 1997, 'Analysis and synthesis in mathematics from the perspective of Charles S. Peirce's philosophy', in M. Otte and M. Panza (eds.), Analysis and Synthesis in Mathematics. History and Philosophy, Kluwer, London, pp. 327-364.

Otte, M.: in press, 'Mathematical epistemology from a semiotic point of view', in A. Sáenz-Ludlow and N. Presmeg (eds.), Special issue on Semiotic Perspectives on Epistemology and Teaching and Learning of Mathematics, Educational Studies in Mathematics 61(1-3).

Peirce, C.S. (CP). Collected Papers of Charles Sanders Peirce, Harvard Univeristy Press, Cambridge, MA.

Peirce, C.S. (EP). The Essential Peirce. Selected Philosophical Writings, Vol. 1 (18671893), Vol. 2 (1893-1913), Indiana University Press, Bloomington and Indianapolis $1992+1998$, IN.

Peirce, C.S. (NEM). The New Elements of Mathematics by Charles S. Peirce, Vol. I-IV (1976), Mouton/Humanities, The Hague-Paris/Atlantic Highlands, NJ.

Peirce, C.S. (SEM). Charles S. Peirce, Semiotische Schriften (Vol. I-III) (1986-1994), Suhrkamp, Frankfurt a.M.

Petrosino, A.J., Lehrer, R. and Schauble, L.: 2003, 'Structuring error and experimental variation as distribution in the fourth grade', Mathematical Thinking and Learning 5(2 and 3), 131-156.

Posner, R., Robering, K. and Sebeok, T.A. (eds.): 1997 ff., Semiotik. Semiotics: Ein Handbuch zu den zeichentheoretischen Grundlagen von Natur und Kultur, Vol. 1-3, de Gruyter, New York.

Presmeg, N.: in press, 'Semiotics and the "connections" standard: Significance of semiotics for teachers of mathematics' in A. Sáenz-Ludlow and N. Presmeg (eds.), Special issue 
on Semiotic Perspectives on Epistemology and Teaching and Learning of Mathematics, Educational Studies in Mathematics 61(1-3).

Radford, L.: 2000, 'Signs and meanings in students' emergent algebraic thinking. A semiotic analysis', Educational Studies in Mathematics 42(3), 237-268.

Radford, L.: in press, 'On meaning, subjectivity, and mathematical objects', in A. Sáenz-Ludlow and N. Presmeg (eds.), Educational Studies in Mathematics, Special Issue on "The Teaching and Learning of Mathematics: Semiotic and Epistemological Perspectives".

Roth, W.-M.: 2003, Toward an Anthropology of Graphing: Semiotic and Activity-Theoretic Perspectives, Kluwer, Dordrecht, The Netherlands.

Roth, W.-M. and McGinn, M.K.: 1998, 'Inscriptions: Towards a theory of representing as social practice', Review of Educational Research 68(1), 35-59.

Sáenz-Ludlow, A.: 2003, 'Classroom discourse in mathematics as an evolving interpreting game', in M. Anderson, A. Sáenz-Ludlow, S. Zellweger and V.V. Cifarelli (eds.), Educational Perspectives on Mathematics as Semiosis: From Thinking to Interpreting to Knowing, Legas, Ottawa, Canada, pp. 253-281.

Sáenz-Ludlow, A.: in press, 'Classroom interpreting games as mediators in the construction of meaning', in A. Sáenz-Ludlow and N. Presmeg (eds.), Educational Studies in Mathematics, Special Issue on "The Teaching and Learning of Mathematics: Semiotic and Epistemological Perspectives".

Sáenz-Ludlow, A. and Presmeg, N. (eds.): in press, Special Issue on "The Teaching and Learning of Mathematics: Semiotic and Epistemological Perspectives".

Saussure, F.d.: 1966(1916), Course in General Linguistics (Cours de Linguistique Gen erale), W. Baskin, Trans., McGraw-Hill, New York.

Seeger, F.: 1998, 'Representations in the mathematical classroom: Reflections and constructions', in F. Seeger, J. Voigt and U. Waschescio (eds.), The Culture of the Mathematics Classroom, Cambridge University Press, Cambridge, UP, pp. 308343.

Sfard, A.: 1991, 'On the dual nature of mathematical conceptions: Reflections on processes and objects as different sides of the same coin', Educational Studies in Mathematics 22, $1-36$.

Simon, M.A.: 1995, 'Reconstructing mathematics pedagogy from a constructivist perspective', Journal for Research in Mathematics Education 26, 114-145.

Steinbring, H.: in press, 'What makes a sign a mathematical sign? - An epistemological perspective on mathematical interaction' in A. Sáenz-Ludlow and N. Presmeg (eds.), Educational Studies in Mathematics, Special Issue on "The Teaching and Learning of Mathematics: Semiotic and Epistemological Perspectives".

Stjernfelt, F.: 2000, 'Diagrams as centerpiece of a Peircean epistemology', Transactions of the Charles S. Peirce Society 36, 357-384.

Van Someren, M., Reimann, P., Bozhimen, H. and De Jong, T. (eds.): 1998, Learning with Multiple Representations, Elsevier Science, Oxford, UK.

Walkerdine, V.: 1988, The Mastery of Reason: Cognitive Development and the Production of Rationality, Routledge, London.

Whitson, J.A.: 1997, 'Cognition as a semiosic process: From situated mediation to critical reflective transcendence', in D. Kirshner and J.A. Whitson (eds.), Situated Cognition: Social, Semiotic, and Psychological Perspectives, Erlbaum, Mahwah, NJ, pp. 97-149.

Whitson, J.A.: 2003, Thinking, Learning, Knowing, Doing, and Becoming: Semiotic and Pragmatic Bases for an Alternative to "Transfer", in Paper presented at the AERA, Chicago. 
ARTHUR BAKKER

Freudenthal Institute, Utrecht University

Aidadreef 12

NL 3561 GE Utrecht

The Netherlands

E-mail: arthur@fi.uu.nl

Fax: +3130-266-0460

Tel.: +3130-263-5538

Present address (After September 2004):

School of Mathematics, Science and Technology

Institute of Education, University of London

23-29 Emerald Street

London WC1N $3 Q S$

United Kingdom

E-mail:a.bakker@ioe.ac.uk

MICHAEL H.G. HOFFMANN

University of Victoria, Canada

Present address (After July 2004): School of Public Policy Georgia Institute of Technology, D.M. Smitth Building 685 Cherry Street

Atlanta

Georgia 30332-0345, U.S.A.

E-mail: michael.hoffmann@pubpolicy.gatech.edu 